\title{
DESAFIOS NA GESTÃO DE UMA ESCOLA ESTADUAL NO PARANÁ/BRASIL A PARTIR DA FILOSOFIA DE LINGUAGEM DE BAKHTIN
}

http://dx.doi.org/10.5902/2318133842801

\author{
Luana Silvy de Lorenzi Tezza Magnin ${ }^{1}$ \\ Adriana Roseli Wunsch Takahashi ${ }^{2}$ \\ Gustavo Henrique Petean ${ }^{3}$ \\ Miriam Aparecida Graciano de Souza Pan ${ }^{4}$
}

\begin{abstract}
Resumo
Atribui-se à educação papel central quanto ao exercício da liberdade, cidadania e de uma sociedade democrática. Contudo, a realidade das escolas públicas aponta para a precarização. Neste artigo propõe-se a contribuir na área de organizações ao analisar os principais desafios na gestão de uma escola pública do Estado do Paraná, por meio de um estudo de caso em uma escola de Curitiba, a partir da perspectiva de Mikhail Bakhtin. Os resultados apontam que os enunciados da profissionalização e eficiência do serviço público atuam sobre a produção de resultados como o Índice Ideb, deixando o processo educativo em sentido amplo em segundo plano. Conclui-se que se faz necessário conhecer a realidade cotidiana das escolas para então propor alternativas que minimizem as dificuldades identificadas.

Palavras-chave: Bakhtin; educação; gestão; políticas públicas.
\end{abstract}

\section{MANAGEMENT CHALLENGES IN A STATE SCHOOL OF PARANÁ FROM BAKHTIN'S LANGUAGE PHILOSOPHY}

\begin{abstract}
Education receives a central role in the exercise of freedom, citizenship, and to enable a democratic society. However, the reality of public schools points to precariousness. The article proposes to contribute in the area of organizations by analyzing the main challenges in the management of a public school in the State of Paraná, through a case study in a school in Curitiba, based on the Mikhail Bakhtin analysis. The results indicate that the statements of professionalization and efficiency of the public service act mainly on the production of results such as the Ideb Index, leaving the educational process in a broad sense in the background. We conclude that it is necessary to know the everyday reality of schools in order to propose alternatives that minimize the identified difficulties.

Key-words: Bakhtin; education; management; public policy.
\end{abstract}

\footnotetext{
${ }^{1}$ Fundação Oswaldo Cruz/PR, Brasil. E-mail: luanasilvy@hotmail.com.

2 Universidade Federal do Paraná, Brasil. E-mail: adrianarwt@terra.com.br.

3 Universidade Federal de Goiás, Brasil. E-mail: gustah@gmail.com.

4 Universidade Federal do Paraná, Brasil. E-mail: miriamagspan@yahoo.com.br.

\begin{tabular}{|l|l|l|l|l|l|} 
Regae: Rev. Gest. Aval. Educ. & Santa Maria & v. 9 & n. 18 & Pub. contínua 2020 & p. 1-17
\end{tabular}
}




\section{Introdução}

○ Brasil são inúmeras as dificuldades que as organizações destinadas ao ensino público enfrentam. Há desafios diários diversos: o salário dos professores tem defasagem, a qualidade do ensino básico é questionada e as condições de trabalho são alarmantes. Uma pesquisa promovida pela Organização para a Cooperação e Desenvolvimento Econômico - OCDE - (2014) apontou que, no Brasil, $12 \%$ dos professores ouvidos afirmaram ser vítimas de agressões verbais ou de intimidação de alunos pelo menos uma vez por semana. Trata-se do índice mais alto entre os 34 países pesquisados: a média entre eles é de 3,4\%.

As condições atuais dos trabalhadores do magistério têm suas raízes no final do século 18 perduraram até meados do século seguinte (Patto, 1990; Russo, 2009). A literatura aponta que dentre os principais problemas identificados nas escolas, que levam à falta de qualidade do ensino público brasileiro, encontram-se: dificuldades na formação dos professores; rotatividade de professores e diretores; ausência de funcionários (Russo, 2009); o processo de adoecimento dos docentes (Penteado; Souza Neto, 2019). A burocracia no repasse de verbas é alta, o que gera barreiras para a manutenção e contratação de profissionais. A rotatividade e a falta de funcionários decorrem da legislação do sistema educacional, que é lenta para a reposição de novos funcionários, e da falta da valorização dos colaboradores no ensino e formação escolar dos alunos (Russo, 2009; Flach, 2012).

Em contraste à situação descrita há apontamentos que indicam que a educação seria condição indispensável para a construção do homem histórico-social. O processo educativo, ao possibilitar a apropriação da cultura e do trabalho coletivo, permite a própria humanização do homem (Beisiegel, 2018; Leontiev, 2004; Rodrigues, 2001). O enunciado da centralidade da educação estende-se a múltiplos discursos humanizadores ou românticos, que depositam à educação a missão de possibilitar o exercício da liberdade, da cidadania, a aquisição de valores e o desenvolvimento integral do homem, assim como de uma sociedade democrática e de bem-estar social, justa e igualitária. Assim, da educação espera-se, também, que seja guardiã dos princípios, da moral, dos bons costumes e a impulsionadora do desenvolvimento da ética e da justiça.

A instituição escolar, portanto, além de responder a uma visão funcionalista de provimento de informações aos seus alunos, visando a prepará-los ao mercado de trabalho ou para o próximo nível escolar (Paro, 2007), cuja ênfase tem sido cada vez maior com o domínio dos enunciados neoliberais das últimas décadas, responde a enunciados que a situam no centro da possibilidade de mudanças políticas, sociais e econômicas (Freire, 1967). Ao mesmo tempo, espera-se que a escola propicie um ambiente seguro em que se possa desenvolver o espírito crítico, a capacidade de análise, desafiando-se as aparências fenomênicas.

A partir da promulgação da LDB e da instituição do planejamento pedagógico das escolas por meio dos chamados projetos político-pedagógicos, entrou em vigor uma lógica de eficiência do serviço público e desburocratização, com menor participação do Estado em todas as esferas governamentais. Tal corrente de modernização e 
profissionalização do serviço público acarretou também na busca pela excelência e pela qualidade do ensino nas escolas públicas com o menor desperdício possível dos recursos públicos, sucedendo a lógica anterior de preocupação com a universalização do ensino básico (Fonseca, 2003; Fonseca; Oliveira, 2009, Zanardini; Blum; Michelon, 2013).

As recentes políticas públicas demandam das organizações escolares maior racionalização e eficiência, de modo que houve um aumento na pressão por melhores indicadores de qualidade de ensino, como o Índice de Desenvolvimento da Educação Básica - Ideb (Fonseca; Oliveira, 2009; Rodrigues; Solano, 2016).

Mediante tal contexto observa-se que as escolas públicas têm sido negligenciadas em investimentos públicos, condições tecnológicas, formação inclusiva, preparação cidadã e profissional, cenário este agravado pelas fragilidades sociais e desigualdades econômicas, vivenciado pelas crianças e adolescentes, e denunciado com frequência na mídia local, nacional e internacional. Necessário considerar, nesse sentido, o processo de desinvestimento na educação, e os investimentos pouco eficientes, como aponta Fraga (2018), em entrevista realizada com o diretor de investimentos educacionais da OCDE, Andreas Schleicher. Outro evento recente são os fechamentos de unidades educacionais em diversos estados brasileiros, comumente relacionado as medidas econômicas realizadas pelos entes federativos (Bringel; Oliveira, 2020).

Assim, neste artigo propõe-se a analisar os principais desafios de gestão enfrentados pelo corpo diretivo da escola estadual selecionada. Compreende-se aqui a gestão escolar em sentido amplo, que ultrapassa a compreensão mainstream da Administração. Ou seja, a proposta é identificar os principais conflitos, as principais tramas que se impõem como desafios aos gestores. Conhecer os desafios é fundamental para impulsionar mudanças, inclusive aquelas que a própria academia poderá iniciar, a partir da reflexão crescente sobre a urgência de maior impacto social da universidade em uma sociedade profundamente desigual e inequânime.

\section{Gestão escolar}

A gestão escolar é um meio para realizar objetivos e diretrizes educacionais, orientando ações educativas pensadas em sentido amplo, o que envolve também conceber a educação em seu sentido social e político. Dessa forma, embora abranja também a administração escolar, é mais ampla que esta última (Lück, 2002; Singh, 2016).

A gestão escolar pode ser segmentada nas seguintes subáreas: gestão de pessoas; gestão pedagógica; gestão das condições de trabalho; gestão financeira (dourado, 2007; veiga, 2013). Essa subdivisão em áreas apresenta um caráter de delimitação de temas, já que na realidade concreta os desafios encontram-se bastante imbricados, trazendo elementos de diversas áreas, ao mesmo tempo.

A área de gestão de pessoas nas escolas públicas envolve a forma de ingresso dos servidores - professores e técnicos -, a avaliação de desempenho dos mesmos, visando a assegurar um alto desempenho e fundamentalmente o controle da subjetividade do trabalhador (Faria, 2017), servindo também como condicionante de sua progressão, e todo relacionamento entre os trabalhadores, alunos, pais, a forma de gestão estabelecida - eleição de diretores, comissões -e as políticas estabelecidas: valores compartilhados, práticas valorizadas. 
Devido a divergências de ideias, ideais e concepções diversas, a instituição escolar precisa lidar com conflitos entre pessoas e seus interesses. Ainda no âmbito da gestão escolar pode-se adotar metas e objetivos conflitantes entre os envolvidos, o que tende a exigir a atenção e o consenso dos gestores e das equipes de trabalho (Veiga, 2013). A falta de regulamentação e clareza de aspectos ligados à gestão de pessoas tende a ampliar os conflitos no que se refere à distribuição de funções e promoção de incentivos. A alta rotatividade de funcionários e elevado número de faltas e afastamentos, aliada à lentidão do processo de reposição de trabalhadores tende a sobrecarregar aqueles em exercício, consistindo esses em aspectos geradores de desmotivação (Russo, 2009; Flach, 2012).

Em relação à gestão pedagógica o projeto político-pedagógico orienta o planejamento escolar, em conjunto com o Plano de Desenvolvimento da Educação, sendo o primeiro voltado para os desafios propriamente pedagógicos. No PPP deve-se abordar temas como o a proposta escolar, que inclui a pedagogia e a filosofia que a fundamenta, as formas de avaliação, a definição de o que e como se ensina; a formação dos professores, e a própria gestão administrativa (Oliveira; Fonseca; Toschi, 2005).

Já a gestão das condições de trabalho envolve a estrutura física da instituição escolar: estrutura elétrica, rede de gás, água e esgoto, sanitários, salas de aula, biblioteca, quadras de esporte, cozinha, sala dos professores, acesso para pessoas com deficiência; recursos e materiais disponíveis: acesso a materiais escolares e de estudo, à tecnologia da informação; condições de limpeza, higiene e segurança ofertadas aos trabalhadores e aos demais usuários da escola. Envolve também o salário e a carga horária de trabalho dos professores, o respeito aos horários de pausa, o acesso à alimentação, a um ambiente seguro, acolhedor e livre de violência. Pesquisas apontam que as condições de trabalho afetam diretamente o fazer do trabalhador e inclusive 0 rendimento dos estudantes (Franco; Bonamino, 2005).

Embora o país seja um dos que proporcionalmente mais investe em educação 5,2\% do PIB em 2016 - a realidade da educação pública, especialmente as condições de trabalho e os resultados - altas taxas de evasão, reprovações e baixo rendimento acadêmico - deixam a desejar, podendo-se problematizar a qualidade dos investimentos e a forma de gestão dos recursos. Outro aspecto relevante em relação à gestão financeira é o processo de descentralização do financiamento da educação, que teve início a partir de 1995, com vistas a atribuir maior autonomia à gestão local. Não obstante, as escolas ainda enfrentam excesso de burocracia para a execução dos recursos, o que dificulta a gestão democrática e autônoma (Russo, 2009; Flach, 2012).

\section{Estratégias de pesquisa}

Diante da importância que os enunciados depositam à educação para a formação de uma sociedade justa, livre, cidadã e igualitária, e das reconhecidas dificuldades que as escolas estaduais enfrentam, o presente artigo faz uma discussão teórico-empírica referente aos desafios de gestão enunciados em uma escola pública na cidade de Curitiba/PR.

Como técnica de coleta de dados foram realizadas observações e entrevistas dialogadas. Foram realizadas três entrevistas abertas, sem roteiro previamente definido, sendo que as entrevistadas ocupavam os cargos de diretora geral, diretora auxiliar e 
pedagoga. A questão norteadora das entrevistas foi a indagação sobre os principais desafios de gestão enfrentados. A cada entrevista foi realizada uma observação participante de cerca de duas a três horas, sendo essa observação realizada antes ou depois das entrevistas, conforme a disponibilidade dos profissionais entrevistados. A observação participante envolveu diversos momentos e espaços da rotina escolar: aulas de educação física no pátio da escola, aulas livres na quadra, conversas dos alunos com as pedagogas, participação em festa de despedida de uma das profissionais da escola, observação da estrutura física, da interação de professores com alunos fora da sala de aula, conversas das diretoras com alunos, pais e professores, dentre outros.

Adotou-se a perspectiva filosófica de linguagem do círculo de Bakhtin (2011). O autor destaca o caráter sócio-histórico da linguagem, assim como o papel do indivíduo como sujeito criador e ativo, mas também - ou por isso mesmo - discursivo, ou seja, histórico, situado em um contexto social, cultural e dialógico. Foi realizado estudo de caso, tal como proposto por Stake (2005). Entende-se que o estudo de um caso em particular deve ser feito considerando-se o contexto econômico, social e político em que está inserido.

Foi realizada a análise dos seguintes documentos: decreto n. 6.094, de 24 de abril de 2007, que dispõe sobre a implementação do Plano de Metas Compromisso Todos pela Educação; nota técnica Índice de Desenvolvimento da Educação Básica - Ideb; Guia prático da gestão escolar (2016) da Secretaria da Educação - Seed/PR. O guia envolve onze eixos, que envolvem alimentação escolar, comunicação, estrutura física e manutenção, gestão financeira, informações educacionais, recursos humanos, tecnologias educacionais, transporte escolar.

Existem, na cidade de Curitiba, 62 e duas escolas estaduais, que atendem a mais de 150.000 alunos matriculados, existindo ainda uma rede conveniada para educação especial de quarenta escolas que atendem a mais de seis mil alunos, conforme dados disponibilizados pelo sítio da Seed/PR.

A busca pela escola foi inicialmente realizada por meio do sítio da Seed/PR. A escolha do caso foi feita com base nos seguintes parâmetros: relevância da organização para o tema estudado; percepção do interesse dos gestores da escola no estudo proposto a partir dos contatos telefônicos; disponibilidade de agenda dos gestores para conceder entrevistas relativamente longas: aproximadamente uma hora de duração cada uma; horário de funcionamento da escola, que inclui os três turnos, o que poderia trazer elementos interessantes de análise e informações relevantes referentes ao seu funcionamento e acessibilidade.

A escola escolhida é localizada em um dos principais bairros na zona Sul da cidade de Curitiba/PR e o horário de seu funcionamento é das $7 \mathrm{~h}$ às $22 \mathrm{~h} 30$. A escola foi criada no final da década de 1950. No período noturno a escola oferta a modalidade de educação de jovens e adultos fase II, ensino fundamental, e ensino médio.

Ao longo da pesquisa, buscamos não tomar a realidade imediata como a realidade em si mesma, conforme alerta Faria (2015). Ainda, em sintonia com a análise bakhtiniana adotada, estivemos atentos às contradições, às vozes silenciadas, às reificações, à sujeição dos sujeitos, aos posicionamentos singulares por eles adotados, às políticas públicas de educação e à forma como estas respondem e reificam determinados enunciados já em evidência (Magnin, 2014).

\begin{tabular}{|l|l|l} 
Regae: Rev. Gest. Aval. Educ. & Santa Maria & v. 9
\end{tabular} ก. 18 Pub. contínua 2020 p. 1-17 
Na perspectiva de Bakhtin a voz representa a forma de um grupo posicionar-se, seja numa política pública, um plano de capacitação, uma prática educativa. A voz de um grupo social pode estar representada na arena de vozes ou silenciada por outra voz, que ascende como única, verdadeira, monovalente, naturalizada em relação a outras. A filosofia discursiva de Bakhtin entende os enunciados como práticas de produção de sentidos, de subjetividades. Nessa concepção ocorre o que se denomina choque de enunciados, os quais instauram práticas discursivas (Bakhtin, 2011; 2012).

\section{Resultados e discussão}

A partir dos depoimentos estruturou-se três eixos temáticos para a interpretação e exposição dos resultados, a partir de enunciados emblemáticos selecionados:

- recursos humanos e condições desumanas: neste eixo são abordadas as condições de trabalho na escola, que envolvem a falta de recursos humanos e materiais e o espaço que é designado à escola nas políticas públicas de educação: como instituição salvadora e amenizadora de situações de violência. Problematiza-se também como essa designação ocupa o grupo diretor da escola com problemas sociais e comportamentais graves e rotineiros, que dificultam sua atuação em projetos de médio e longo prazo, que trabalhem no sentido da efetiva melhora da qualidade do ensino.

- Cultura do mínimo e do não dá nada: neste eixo é trabalhada a visão compartilhada por diversos grupos acerca da educação no Brasil, em sintonia com o enunciado da nova administração pública: investimento mínimo e busca pela máxima rentabilização de resultados. É abordada também a falta de preparo do sistema escolar para lidar com o que escapa à norma e ao padrão pré-estabelecido, no que se refere a pessoas e infraestrutura;

- Fazer o melhor do pior: estudar é bom, mas só interessa o começo e o fim: neste eixo é discutida a forma como as políticas públicas de educação adotadas, com ênfase para o índice Ideb, estimulam práticas específicas de ensino e avaliação, produzindo modos de subjetividade voltados ao produtivismo de resultados. É problematizada a postura finalística e utilitarista atribuída à educação no cenário nacional e sua articulação com políticas internacionais neoliberais, que vêm ganhando espaço na arena de vozes.

Em cada um dos eixos foi considerado o contexto mais amplo no qual a escola está inserida, o que envolve as políticas públicas de educação. Assim, ainda que se tenha utilizado o estudo de caso, a análise não ficou restrita à escola escolhida, pois entende-se que a instituição escolar não pode ser estudada isolada de seu contexto. Os enunciados referem-se sempre a determinado contexto (Bakhtin, 2011) econômico, social, histórico, político, que é articulado internacionalmente, e que interfere nas decisões e políticas nacionais, estaduais e locais.

\section{- Recursos humanos e condições desumanas}

Partindo-se do estudo empírico da escola selecionada, diversos fatores confirmam a precarização das condições de trabalho nas escolas públicas, conforme apontado pelos pesquisadores (Flach, 2012; Libâneo, 2012; Patto, 2007; Russo, 2009; Saviani, 1997), tais como: falta de professores; falta de vigilantes para trabalhar na portaria da escola; falta de bibliotecário e inspetor; excesso de faltas de professores ou stress dos profissionais; excesso de pessoas cumprindo penas restritivas de direito na escola. 
No que se refere aos recursos materiais, notou-se: estrutura física precária; pintura interna e externa da escola deteriorada e apagada, excesso de pichações; quadra em cimento, sem demarcação de linhas, sem cobertura, e imensa dificuldade em viabilizar a sua reforma e cobertura; banheiros sem assentos, nem papel higiênico ou papel toalha; demora na liberação financeira e dificuldade para a execução de orçamentária; dificuldades no provimento da merenda escolar; espaço de circulação interna da escola todo em cimento, sem pintura, deteriorado.

De acordo com o que foi relatado, o stress dos profissionais envolve lidar com muitas situações inusitadas que acontecem na escola, tais como: brigas, tráfico de drogas, violência, problemas de relacionamento entre alunos, professores e direção. Todos esses fatores favorecem a construção de um ambiente instável, em que os professores trabalham com as portas abertas, em que ao mesmo tempo que redigem documentos, fazem ligações e estão com os olhares e ouvidos atentos aos alunos, funcionando como espécie de inspetoras dos mesmos. Verifica-se que à escola têm sido de fato designados outros papéis que não prioritariamente o do ensino, atuando como mediadora de conflitos e amenizadora de situações de violência (Patto, 2007; Russo, 2009).

O tráfico de drogas na escola estudada é frequente, sendo que o corpo diretor afirmou fazer recorrentes verificações nos banheiros, especialmente sobre as divisórias que separam os vasos, local identificado como preferido para o tráfico. O grupo gestor está também atento aos códigos utilizados pelos alunos, siglas que escrevem sobre o chão, que anunciam que haverá briga na saída da escola. Essas brigas referem-se a grupos de vilas distintas que a escola atende. Foi esclarecido que, embora a escola esteja situada em um bairro considerado muito bom, atende a alunos de bairros mais distantes e desprivilegiados, já que as famílias que de fato moram no local onde a escola está localizada optam por matricular seus filhos em escolas particulares.

Existe falta de profissionais na escola estudada. Fica evidente, numa tentativa de compensar tais ausências, ao se constatar que existem vagas para dez pessoas cumprirem penas restritivas de direito, exercendo trabalho comunitário na escola. Tais pessoas preenchem assim necessidades básicas da escola, evidenciam a precarização da força de trabalho no âmbito escolar.

Diante dessa escassez de profissionais um dos problemas enfrentados pelo grupo gestor da escola é o que fazer com os alunos quando os professores faltam. A diretora mostrou à pesquisadora uma pasta com dezenas de atestados médicos, que seriam todos referentes ao mês corrente. De acordo com um estudo realizado pela Secretaria Estadual de Administração e Previdência, o Estado do Paraná tem oitenta mil professores cadastrados na rede e por ano, doze mil docentes são afastados de suas funções: "a principal causa do pedido de licença ocorre com o diagnóstico de uma doença, ocasionada pelo estresse em sala de aula e também pela falta de recursos técnicos que facilitem o trabalho nas instituições de ensino" (Gestrado, 2020, p. 1).

Quando as faltas dos professores são previstas antecipadamente, já existe uma rotina estruturada a ser seguida na escola, o que confirma o quanto essas faltas são, de fato, frequentes: o cronograma de aulas é reorganizado, elabora-se um bilhete para os pais dos alunos, informando que as aulas da série em questão iniciarão mais tarde ou terminarão mais cedo, para que os pais assinem e responsabilizem-se pelos filhos. De 
fato, confirma-se a tese de que os jovens atualmente são vistos como um grupo social de risco, que deve ser vigiado e acompanhado, assumindo então a escola uma função de prevenção da criminalidade e da violência (Patto, 2007; Sposito, 2008).

A escola possui acordo com duas universidades em que os alunos participam de projetos de iniciação à docência por meio do Programa Institucional de Bolsa de Iniciação à Docência. $\mathrm{O}$ corpo diretivo da escola demonstrou valorizar bastante essa iniciativa, pois elas trariam assuntos diferentes que despertariam o interesse dos alunos, ligados às disciplinas de artes, música, história, entre outros.

Apesar de toda a precariedade de condições de trabalho, que envolvem recursos materiais e humanos, observou-se um clima organizacional aparentemente amigável, em que os profissionais se permitem fazer brincadeiras, rir, descontrair o ambiente que de outra forma poderia ser insuportável. É possível que o ambiente precário justamente fomente a união como estratégia de sobrevivência, o que precisaria ser investigado em maior profundidade.

\section{- Cultura do mínimo e do não dá nada}

As entrevistadas criticaram a cultura do mínimo e do não dá nada, que seria próprio à postura dos alunos, que buscariam fazer o mínimo para por sua vez garantir a nota mínima exigida pela escola, sem existir um real comprometimento com o ensino e a aprendizagem. Foram apresentadas diversas queixas do grupo gestor referentes ao valor insuficiente disponibilizado à escola para o seu adequado funcionamento, à lentidão na liberação das verbas, à dificuldade em se realizar as compras conforme as determinações legais, à esporadicidade no provimento de alimentação proveniente do projeto de agricultura familiar, entre outros problemas relacionados à merenda escolar, como o provimento de quantidades de alimentos insuficientes para atender ao número de alunos da escola nos três períodos de funcionamento.

Percebe-se o risco de se tomar um enunciado isoladamente, que responsabiliza apenas o aluno, o professor, o governo, a direção, a escola, ou os pais. Verifica-se a falta de priorização das demandas educacionais, mas isso não ocorre apenas por um grupo específico. Essa percepção está de acordo com a voz de uma das entrevistadas, quando afirma: "estudar é bom, mas só interessa o começo e o fim". Essa voz evidencia a centralidade dos resultados sobre os processos. Os efeitos dessa priorização dos resultados podem ser constatados nas escolas públicas brasileiras, em que o processo de aprendizado deixa de ser o foco das políticas públicas de educação.

Verificou-se que a escola estudada não atende aos alunos do bairro em que está situada, sendo que eles provêm de vilas vizinhas, comunidades bastante carentes, famílias com baixa escolaridade e que, conforme apontaram os profissionais, famílias que não acompanham o processo de ensino. Verificou-se que as escolas públicas estaduais médias costumam atender justamente às famílias marginalizadas, excluídas socialmente, que não possuem formação que ajude a cobrar os seus direitos por uma educação pública, gratuita e de qualidade.

Essa designação da escola como instituição que deve trabalhar no sentido de prevenir a delinquência social, evitar a violência, sanar problemas como o acesso dos jovens às drogas, necessariamente secundariza o seu papel como local de emancipação 
social e questionamento. Segundo Patto (2007) "está aberta a porta à destituição da escola como instituição de ensino e à transformação dela em lugar de detenção maquiada dos filhos dos pobres e de violência sem precedentes" (p. 245).

Chamou atenção o grande número de interrupções ao longo das entrevistas realizadas. Eram alunos e professores que solicitavam o acesso a materiais de uso bastante rotineiro em uma instituição escolar: folhas de avaliação, fita adesiva, grampeador, livros, chave de salas, entre outros, o que aponta certa restrição do acesso a esses itens. O grupo gestor da escola ocupa-se da gestão de materiais, com vistas a controlar e evitar o desperdício, em sintonia com a proposta de redução de custos e máxima eficiência. Com isso a dedicação às atividades propriamente pedagógicas e de gestão, de planejamento de ensino, são secundarizadas. Ou seja, o enunciado da eficiência e maximização de resultados traz consigo aspectos que por vezes não são discutidos em profundidade.

Outro aspecto que evidencia a 'cultura do mínimo' é a determinação legal de que apenas alguns alunos possuem direito a tutores em sala de aula. Alunos que possuem necessidades especiais e que precisam de apoio para que os processos de inclusão de fato aconteçam só têm direito à tutoria se tiverem diagnósticos fechados, previstos no Manual diagnóstico e estatístico de transtornos mentais (American Psychiatric Association, 2014).

$\mathrm{Na}$ escola em questão havia um aluno que demonstraria possível atraso de desenvolvimento e apresentava comportamentos bastante violentos: no dia anterior a uma das entrevistas havia quebrado os vidros da sala de aula. $O$ caso apontado mostra o quanto a inclusão ainda é um desafio na rede pública e o quanto há falta de preparo do corpo diretivo, dos professores e do todo escolar para lidar com situações desse tipo, o que gera uma individualização do problema. Diante da falta de recursos o aluno é responsabilizado por seus problemas de violência e a família é chamada a resolver o problema, sem apoio governamental ou institucional.

Em relação à infraestrutura e recursos materiais a quadra esportiva aparece como um símbolo da dificuldade de se fazer reformas que atendam às necessidades específicas da escola, sendo um excelente emblema referente à 'cultura do mínimo'. Há vários anos as diretoras têm solicitado junto à Secretaria de Educação a reforma da quadra de esportes. A justificativa que as diretoras receberam é de que a quadra não possui medida padrão, o que impossibilitou que a escola fosse contemplada com a reforma prevista para diversas escolas da região. No entanto, as medidas da quadra da escola seriam inferiores até mesmo daquelas quadras de medidas especiais, o que serviu novamente de justificativa para que o colégio não fosse contemplado. A narrativa referente à quadra evidencia o quanto não se está preparado para lidar com as diferenças locais, as necessidades específicas de cada escola. A narrativa ainda nos faz questionar o quanto as políticas públicas de educação limitam-se a trabalhar com padrões e não tem conseguido enfrentar as especificidades e singularidades presentes no ambiente escolar.

Junto à estrutura principal da escola existe um espaço que é destinado à residência do permissionário, um policial militar. Trata-se da casa do zelador, um projeto do Estado que tem como objetivo ampliar a segurança dos espaços escolares e da comunidade. Durante as entrevistas houve a saída de um policial e a entrada de um outro na escola. 
Segundo uma das diretoras o momento de mudança do policial militar era propício à demolição do espaço do zelador, transferindo a casa para o local do estacionamento, o que permitiria a ampliação do tamanho da quadra esportiva e finalmente possibilitaria a sua reforma. No entanto, a reforma não foi autorizada. Verificou-se que esses policiais, além de ajudar na segurança da escola, principalmente aos fins de semana, atuam também como ajudantes informais, trocam lâmpadas, consertam a fiação da escola, entre outros.

Tanto o caso do aluno, quanto o da quadra evidenciam o quanto a 'cultura do mínimo' faz parte do sistema educacional, que trabalha com padrões e que apresenta dificuldades para lidar com as especificidades locais. Como lidar com o aluno violento que quebrou o vidro da escola? Como reformar uma quadra que é tão pequena que não se encaixa no padrão e nem no projeto especial para quadras de medidas reduzidas?

- Fazer o melhor do pior: estudar é bom, mas só interessa o começo e o fim

Diante de um cenário de violência, drogas, desrespeito aos professores e à população, falta de estrutura física e de pessoas, resta à escola amenizar problemas, fazer 'o melhor do pior', conforme enunciado por uma das entrevistadas, em referência ao programa de avaliação do ensino básico. A aprendizagem deixa de ser o principal objetivo de estar na escola. Notou-se a preocupação das diretoras com a significativa redução do número de alunos nas turmas e o risco que turmas sejam fechadas.

Outro enunciado emblemático foi o de que 'estudar é bom, mas só interessa o começo e o fim', em referência à forma como os pais pouco valorizam o ensino e o aprendizado: reconhecem sua importância, mas com frequência não querem se envolver com o processo, acompanhar os filhos, o seu desempenho, as faltas. O grupo gestor queixou-se de 'pais que são advogados dos filhos' e da necessidade de se 'munir de provas para poder conversar com os pais dos alunos. Essa dificuldade fomentou inclusive uma prática escolar de exigir dos discentes a assinatura em uma folha de avaliação na qual o professor registra o nome dos alunos que não realizaram determinada atividade solicitada. O tempo investido nesse registro certamente reduz o tempo dedicado propriamente ao processo de ensino e aprendizagem.

Por outro lado estudos apontam o tédio crônico na sala de aula como um sintoma emblemático de repetidos equívocos no âmbito educacional. Alguns culpabilizam a falta da utilização de recursos tecnológicos, outros as aulas maçantes e o distanciamento da realidade dos alunos. Uma análise mais abrangente do cenário educacional brasileiro, porém, mostra que essa concepção finalística em relação à educação não é apenas compartilhada pelos alunos e suas famílias, mas pelas próprias políticas de educação brasileiras. Interessa ter as crianças e jovens matriculados na escola - fora das ruas -, e a apresentação de bons índices para serem divulgados internacionalmente (Libâneo, 2012).

Por meio do decreto n. 6.094/2007, que visa a "mobilização social pela melhoria da qualidade da educação básica" (Brasil, 2007), foi oficializado o Índice de desenvolvimento da Educação Básica - Ideb - que no artigo $3^{0}$ estipula a forma como a qualidade da educação básica será mensurada: 
A qualidade da educação básica será aferida, objetivamente, com base no Ideb, calculado e divulgado periodicamente pelo Inep, a partir dos dados sobre rendimento escolar, combinados com o desempenho dos alunos, constantes do censo escolar e do Sistema de Avaliação da Educação Básica - Saeb -, composto pela Avaliação Nacional da Educação Básica Aneb - e a Avaliação Nacional do Rendimento Escolar - Prova Brasil. (Brasil, 2007)

O decreto prevê, no parágrafo único do artigo $3^{\circ}$ que "o Ideb será o indicador objetivo para a verificação do cumprimento de metas fixadas no termo de adesão ao compromisso" (Brasil, 2007). Nota-se a ênfase do documento pela mensuração de resultados de forma objetiva. De acordo com a nota técnica Índice de desenvolvimento da Educação Básica - Ideb, o índice é resultado do produto entre o desempenho e o rendimento escolar. $\mathrm{O}$ desempenho refere-se à nota média dos alunos nas disciplinas de língua portuguesa e matemática, enquanto que o rendimento escolar se refere ao tempo médio de conclusão de uma série. Segundo a nota técnica um sistema educacional que reprova sistematicamente seus estudantes, fazendo com que grande parte deles abandone a escola antes de completar a educação básica, não é desejável.

Pela análise do texto, tomado como enunciado, observa-se que o abandono escolar estaria, nessa visão, diretamente ligado à reprovação sistemática. $O$ aluno abandona a escola apenas porque reprova? Quais são os outros fatores que são silenciados quando se aponta a reprovação como a grande vilã de um ensino desejável? Será que aluno poderia abandonar a escola porque precisa trabalhar para ajudar a família, ou porque não se sente motivado, ou porque sua percepção da aprendizagem é insignificante?

Com a implantação desse índice a escola se torna corresponsável pelas faltas, pelas taxas de abandono e inclusive pelas notas de seus alunos. Atrelar o índice de faltas e abandono escolar à nota da escola a qual o aluno estava matriculado é atribuir à escola a responsabilidade de retenção dos alunos, conforme aponta o grupo gestor e os documentos analisados.

Essa tese vai ao encontro da análise de Patto (2007) de que a escola está sendo concebida como uma instituição salvadora, cuja função seria afastar os jovens e crianças das ruas, reduzir a criminalidade, ensinar os bons costumes. Isso pode ser evidenciado na escola em questão pela implantação do Projeto valores, que tem como principal objetivo resgatar valores e princípios, como o respeito, e diminuir os índices de violência, o envolvimento dos alunos em brigas, entre outros. Após a implantação do projeto valores, que trabalha com ações de conscientização, afirmou-se ter sido reduzido o número de brigas entre grupos de alunos.

O projeto envolve atribuir parte da nota do aluno em cada uma das matérias a requisitos comportamentais, de modo que o aluno que se envolve em brigas tem sua nota reduzida em todas as matérias. O Projeto valores é motivo de orgulho para o corpo diretor da escola, que afirma que problemas de brigas e violência reduziram bastante após a sua implementação. Fica claro como a política pública de educação adotada pelo governo incentiva formas específicas de subjetividade, atuação e posicionamentos objetivos, implementação de programas e projetos locais que busquem responder - obediente ou criticamente - às demandas instauradas pela política pública. 
Nesse mesmo sentido, foi também implementado na escola o Projeto leitura, que envolve o direcionamento de vinte minutos por dia para que todos os alunos e funcionários da escola parem suas atividades para ler um livro de sua preferência. Com isso a escola visa incentivar o hábito de leitura e reduzir a violência.

Outro ponto a ser discutido, que se relaciona ao 'fazer o melhor do pior', é o próprio falseamento de resultados que o próprio sistema de avaliação incitaria, em sua avaliação objetiva. Segundo as entrevistadas existe pressão externa e interna para que a escola fique bem classificada no índice, já que o mesmo funciona como uma espécie de vitrine da escola, pois é a forma como a escola será vista perante a comunidade, perante o governo, e perante os próprios funcionários e professores. Assim, se for possível evitar uma reprovação por faltas, ou por notas insuficientes, a escola o fará. Desse modo, as notas, mais que servir como referência aos alunos, servem a um índice pelo qual a própria escola é avaliada.

$\mathrm{Na}$ escola estudada as diretoras são também pedagogas e enfocam os problemas principalmente comportamentais, e, quando muito, pedagógicos e educacionais. A preocupação com planejamento estratégico, gestão financeira, gestão de pessoas parece ser mínima frente aos problemas sociais, comportamentais e operacionais enfrentados cotidianamente pelo grupo diretivo. Uma das diretoras entrevistadas enunciou a fala de um dos alunos da escola, que em uma discussão que envolvia aspectos comportamentais e falta de respeito teria afirmado: 'eu não respeito a minha mãe, vou respeitar o professor?

$\mathrm{Na}$ escola foi ainda constatada a individualização da violência pelo grupo gestor: "Às vezes é imaturidade, tem o meio social, o grupo os transforma. Mas é um, dois alunos que tem esse comportamento, e influenciam os outros". Percebe-se que mesmo os próprios profissionais que dirigem a escola, apesar de ocuparem-se com muita frequência de problemas sociais, por vezes situam a violência como um problema individual de um, dois alunos.

Fazer o melhor do pior envolve também a escola atuar como um agente multitarefas: a escola deve gerenciar seu dinheiro, fazer as compras de materiais permanentes e de consumo, ser inovadora e criativa nos cardápios das merendas com reduzidas opções de alimentos de baixo custo, apresentar bons índices, trabalhar a favor da redução das taxas de faltas e de abandono da escola, reduzir os índices de violência, vigiar o tráfico de drogas, fomentar valores, motivar professores mal pagos e estressados, e, quando possível, ensinar.

Evidencia-se que a escola pública recebe um público determinado, marginalizado, excluído socialmente na perspectiva do acolhimento social (Patto, 2007, Libâneo, 2012). Vale ressaltar que o usuário da escola estadual pública é, na grande maioria das vezes, aquele que provém de uma família que não pode pagar por uma educação de qualidade. A falha na proposta constitucional de oferecer uma educação pública, gratuita e de qualidade afeta uma parcela específica da população.

De fato, a escola reflete e retrata políticas públicas de educação que tendem a reforçar enunciados já em evidência, e desprezar outros. A adoção de determinadas políticas públicas não se dá ao acaso, mas são propostas na medida em que são convenientes e servem a produzir determinadas formas de subjetivação, conforme apontam estudiosos de Bakhtin (Machado; Pan, 2012; 2014).

\begin{tabular}{|l|l|l|l|l|r|}
\hline Regae: Rev. Gest. Aval. Educ. & Santa Maria & v. 9 & n. 18 & Pub. contínua 2020 & p. $1-17$ \\
\hline
\end{tabular} 


\section{Conclusões}

A Constituição Federal de 1988 e a LDB asseguraram a educação de qualidade enquanto direito de todo cidadão. No entanto, a garantia do direito no país, enquanto prática social, necessita ainda percorrer um longo caminho. Note-se que a educação de qualidade não pode prescindir de priorização de investimentos, recursos e de uma gestão adequada. Os problemas da educação básica pública no país, embora diretamente afetem apenas a parcela desprivilegiada da população, está formando cidadãos com qualificação insuficiente, resignados e pouco críticos. A escola enquanto instituição de acolhimento social e de minimização de problemas sociais que não são enfrentados em outras esferas, tem atingindo seu objetivo? Que desafios os gestores enfrentam no seu cotidiano e de que forma eles comprometem o propósito e a qualidade educacional? Verificou-se que, de fato, o quadro diretivo da escola partilha de acentuada preocupação social e pedagógica, ao atuar também como instituição de acolhimento social, mas as dificuldades de gestão têm limitado significativamente a dedicação dos dirigentes à implementação de estratégias de gestão com foco na qualidade do ensino.

Neste cenário as principais dificuldades identificadas foram relativas às condições desumanas de trabalho, à cultura do fazer 'o mínimo' associado ao 'máximo resultado', com ênfase sobre o produtivismo, a busca por resultados aliada ao seu falseamento nas mais diversas esferas - políticas públicas, índice lbeb, posicionamento de pais e alunos -, e a estratégia administrativa de tentar fazer o melhor com o que se tem disponível para as atividades administrativas e pedagógicas.

Deste contexto tem emergido inúmeras dificuldades específicas que comprometem o tempo e a energia dos gestores que deveriam e gostariam de centrar esforços nas melhorias destas organizações. Neste cenário cabe uma reflexão de todos os agentes da sociedade: formuladores de políticas públicas, gestores municipais e estaduais, pais de alunos, profissionais de outras áreas. Se a realidade das organizações públicas educacionais traz consequências para toda a sociedade, cabe questionar como cada segmento poderia intervir de forma a contribuir na superação das dificuldades encontradas nessas organizações.

Este estudo não está isento de limitações. Entre elas, pode-se citar a adoção da filosofia da linguagem de Bakhtin como estratégia de análise. Esta adoção exige um estudo situado sócio-historicamente, a articulação com leituras críticas, a leitura de documentos enquanto enunciados, a análise dos próprios enunciados aos quais aqueles respondem, a contraposição histórica para a identificação, seleção e exposição de vozes silenciadas e a construção de um espaço de posicionamento e autoria do pesquisador que exige ser constantemente amadurecido e refinado. Ou seja, trata-se de um posicionamento que ao mesmo tempo em que pode ser lido como uma limitação enquanto perspectiva específica elaborada a partir de múltiplos enunciados.

Tendo em vista o objetivo principal da pesquisa, as entrevistas foram realizadas apenas com o grupo gestor, ou seja, obteve-se a manifestação de um grupo específico que está à frente da instituição. Não foram ouvidos nesta pesquisa outros grupos, mais distantes da esfera de decisão, como as auxiliares de limpeza, as pessoas que cumprem 
pena alternativa na escola, os alunos considerados violentos, os professores contratados em regime de processo seletivo simplificado, entre tantos outros grupos que vivem o cotidiano escolar e que poderiam contribuir para a construção de uma arena mais polifônica.

Destas limitações emergem novas possibilidades de estudos futuros, por meio de pesquisas sobre gestão de organizações educacionais que visem a auxiliar os grupos gestores das escolas a enfrentar seus desafios, considerando-se os desafios pedagógicos e a realidade cotidiana das escolas. Na dimensão prática este estudo contribui com reflexões para os gestores das escolas e para os pesquisadores sobre novos caminhos necessários para a construção conjunta de soluções. As entrevistadas demonstraram descrença com programas de capacitação do governo que delegam à escola a formação continuada de seus professores por meio de temas e pacotes prontos, que não atendem aos interesses e muito menos às necessidades dos profissionais da educação.

Em suma, as políticas públicas de educação e a gestão escolar devem realizar a escuta daqueles que enfrentam e fazem a gestão diária das escolas, lidando com dilemas práticos e vidas reais, que exigem soluções imediatas. Pacotes prontos, apartados da realidade das escolas, que vêm ensinar, à distância, como se faz a gestão escolar, causam revolta e indignação aos trabalhadores que a enfrentam diariamente. Para atuar no sentido da efetiva melhora da qualidade do ensino, as políticas públicas e os projetos delas decorrentes devem ser concebidos a partir da reflexão sobre o processo educacional, secundarizando a ênfase sobre a forma de apresentação dos resultados, ainda que os modelos atuais de avaliação de políticas, programas de pós-graduação e inclusive pesquisadores valorizem apenas certas produções.

\section{Referências}

AMERICAN PSYCHIATRIC ASSOCIATION. DSM-5: manual diagnóstico e estatístico de transtornos mentais. Porto Alegre: Artmed, 2014.

BAKHTIN, Mikhail. A filosofia do ato responsável. São Paulo: Pedro e João, 2012.

BAKHTIN, Mikhail. Estética da criação verbal. São Paulo: Martins Fontes, 2011.

BEISIEGEL, Celso de Rui. Educação popular e ensino superior em Paulo Freire. Educação e Pesquisa, São Paulo, v. 44, 2018, p. 1-19.

BRASIL. Decreto n. 6.094 de 24 de abril de 2007, que dispõe sobre a implementação do plano de metas compromisso todos pela educação, 2007.

BRASIL. MEC integra programas para intensificar a alfabetização. Disponível em http://portal.mec.gov.br/busca-geral/211-noticias/218175739/35051-mec-integraprogramas-para-intensificar-a-alfabetizacao. Acesso em 8 ago. 2017.

BRINGEL, Patrícia; OLIVEIRA, Rafael. Governo confirma o fechamento de 20 escolas em Goiás. G1 Go. Goiânia, p. 1-1. 08 jan. 2020. Disponível em: https://g1.globo.com/go/goias/noticia/2020/01/08/governo-confirma-o-fechamento-de-20escolas-em-goias-veja-lista.ghtml. Acesso em: 06 mar. 2020.

DOURADO, Luís Fernando. Políticas e gestão da educação básica no Brasil: limites e perspectivas. Educação e Sociedade, Campinas, v. 28, n. 100, 2007, p. 921-946. 
FARIA, José Henrique. Análise de discurso em estudos organizacionais: as concepções de Pêcheux e Bakhtin. Teoria e Prática em Administração, João Pessoa, v. 5, n. 2, 2015, p. 51-71.

FARIA, José Henrique. Poder, controle e gestão nas organizações. Curitiba: Juruá, 2017.

FONSECA, Marília. O projeto político-pedagógico e o plano de desenvolvimento da escola: duas concepções antagônicas de gestão escolar. Caderno Cedes, Campinas, v. 23, n. 61, 2003, p. 302-318.

FONSECA, Marília; OLIVEIRA, João Ferreira. A gestão escolar no contexto das recentes reformas educacionais brasileiras. Revista Brasileira de Política e Administração da Educação, Goiânia, v. 25, n. 2, 2009, p. 233-246.

FLACH, Simone de Fátima. Entraves na ação dos gestores de instituições de educação infantile, Plures Humanidades, Ribeirão Preto, v. 13 n. 2, 2012, p. 337-352.

FRAGA, Érica. Investimento em educação no Brasil é baixo e ineficiente: Diretor da OCDE diz que países com sucesso na área a elegeram como prioridade. Folha de São Paulo. São Paulo, p. 1. 19 fev. 2018. Disponível em: https://www1.folha.uol.com.br/educacao/2018/02/investimento-em-educacao-no-brasil-ebaixo-e-ineficiente.shtml. Acesso em 5 mar. 2020.

FRANCO, Creso; BONAMINO, Alicia. A pesquisa sobre característica de escolas eficazes no Brasil: breve revisão dos principais achados e alguns problemas em aberto. Revista do Programa de Pós Graduação: Educação online PUC, Rio de Janeiro, n. 1, 2005, p. 2-13.

FREIRE, Paulo. Educação como prática da liberdade. Rio de Janeiro: Paz e Terra, 1967. GESTRADO. Por ano, 15\% dos professores da rede estadual do Paraná são afastados. Disponível em http://gestrado.net.br/?pg=noticia\&id=383\&L=. Acesso em 31 mar. 2020.

LEONTIEV, Alexis Nikolaevich. O desenvolvimento do psiquismo. São Paulo: Centauro, 2004.

LIBÂNEO, José Carlos. O dualismo perverso da escola pública brasileira: escola do conhecimento para os ricos, escola do acolhimento social para os pobres. Educação $e$ Pesquisa, São Paulo, v. 38, n. 1, 2012, p. 13-28.

LÜCK, Heloísa et al. $A$ escola participativa: o trabalho do gestor escolar. Rio de janeiro: DP\&A, 2002.

MACHADO, Jardel Pelissari; PAN, Miriam Aparecida Graciano de Souza. Do tudo ao nada: políticas públicas e a educação especial brasileira. Educação \& Realidade, Porto Alegre, v. 37, n. 1, 2012, p. 273-294.

MACHADO, Jardel Pelissari; PAN, Miriam Aparecida Graciano de Souza. Política pública e subjetividade: a assistência estudantil na universidade. Textos \& Contextos, Porto Alegre, v. 13, n. 1, 2014, p. 184-198.

MAGNIN, Luana Silvy Lorenzi Tezza. Pobres competentes: o enunciado das (in)competências na administração pública federal e a produção subjetiva do trabalhador. Curitiba: UFPR, 2014. 124F. Dissertação (mestrado em Psicologia). Universidade Federal do Paraná.

OLIVEIRA, João Ferreira; FONSECA, Marília; TOSCHI, Mirza Seabra. O programa Fundescola: concepções, objetivos, componentes e abrangência - a perspectiva de melhoria da gestão do sistema e das escolas públicas. Educação e Sociedade, Campinas, v. 26 , n. 90,2005 , p. 127-147. 
PARO, Vitor Henrique. Gestão escolar, democracia e qualidade do ensino. São Paulo: Ática, 2007.

PATTO, Maria Helena Souza. A produção do fracasso escolar: histórias de submissão e rebeldia. São Paulo: T. A. Queiroz, 1990.

PATTO, Maria Helena Souza. Escolas cheias, cadeias vazias: nota sobre as raízes ideológicas do pensamento educacional brasileiro. Estudos Avançados, São Paulo, v. 21, n. 61, 2007, p. 243-266.

PENTEADO, Regina Zanella; SOUZA NETO, Samuel de. Mal-estar, sofrimento e adoecimento do professor: de narrativas do trabalho e da cultura docente à docência como profissão. Saúde e Sociedade, São Paulo, v. 28, n. 1, 2019, p. 135-153.

RODRIGUES, Neidson. Educação: da formação humana à construção do sujeito ético. Educação e Sociedade, Campinas, v. 22, n. 76, 2001, p. 232-257.

RODRIGUES, Rubens Luiz; SOLANO, Cleonice Halfeld. Reestruturação do Estado brasileiro e o PDE-Escola: implicações para a gestão da escola pública. Educação em Revista, Marília, v. 17, n. 1, 2016, p. 7-18.

RUSSO, Miguel Henrique. Problemas centrais da gestão na escola pública e sua inciência na prática cotidiana segundo os gestores, RBPAE - Revista Brasileira de Política e Administração da Educação, Goiânia, v. 25, n. 3. 2009, p. 455-471.

SAVIANI, Demerval. Escola e democracia. São Paulo: Autores Associados, 1997.

SINGH, Ananda Silva. Grupos de interesses e as práticas de gestão na escola pública básica: um estudo de multicasos. Uberlândia: UFU, 2016. 159f. Dissertação (Mestrado em Administração). Universidade Federal de Uberlândia.

SPOSITO, Marília Pontes. Trajetórias na constituição de políticas públicas de juventude no Brasil. In: FREITAS, Maria Virgínia de; PAPA, Fernanda de Carvalho (org.). Políticas públicas, juventude em pauta. São Paulo: Cortez/Ação Educativa, 2008, p. 57-74.

STAKE, Robert. Qualitative case studies. In: DENZIN, Norman K; LINCOLN, Yvonna S (eds.). The Sage handbook of qualitative research. Thousand Oaks: Sage, 2005, p. 45-72.

VEIGA, IIma Passos Alencastro. A escolar em debate: Gestão, projeto político-pedagógico e avaliação. Revista Retratos da Escola, Brasília, v. 7, n. 12, 2013, p. 159-166.

ZANARDINI, Isaura Monica Souza; BLUM, Márcia Sabina Rosa; MICHELLON, Edimor Antonio. Uma análise das políticas de gestão escolar no Paraná e no Brasil entre os anos de 1980 e 2006. Revista Educação e Fronteiras, Dourados, v. 3, n. 7, 2013, p. 131-139.

Luana Silvy de Lorenzi Tezza Magnin é analista de Gestão pela Fiocruz/PR. Orcid: https://orcid.org/0000-0002-3330-9835.

Endereço: Rua Prof. Algacyr Munhoz Mader, 3775 - 81310-020 - Curitiba - PR Brasil.

E-mail: luanasilvy@hotmail.com. 
Adriana Roseli Wunsch Takahashi é professora na Universidade Federal do Paraná.

Orcid: https://orcid.org/0000-0002-4738-5273.

Endereço: Av. Pref. Lothario Meissner, 632, 2a andar - 80210-170 - Curitiba - PR Brasil.

E-mail: adrianarwt@terra.com.br.

Gustavo Henrique Petean é professor na Universidade Federal de Goiás, Regional Goiás e tem doutorado em Administração na UFMS.

Orcid: https://orcid.org/0000-0003-1248-6418.

Endereço: Avenida Bom Pastor, 200 - 76600-000 - Goiás - GO - Brasil.

E-mail: gustah@gmail.com.

Miriam Aparecida Graciano de Souza Pan é professora na Universidade Federal do Paraná.

Orcid: https://orcid.org/0000-0002-9704-6958.

Endereço: UFPR, Dep. de Psicologia - Santos Andrade, 2ㅇandar, sala 215 - 80060246 - Curitiba - PR - Brasil.

E-mail: miriamagspan@yahoo.com.br.

Recebido em 10 de março de 2020.

Aceito em 27 de abril de 2020.

(c) (i) 